\title{
Letter to Editor COVID-19 outbreak and medical waste: Challenge in hand
}

\author{
Hassan H. Musa ${ }^{1}$, Taha H. Musa ${ }^{2}$, Idriss H. Musa ${ }^{4}$, Olayinka Oderinde ${ }^{5}$ \\ ${ }_{1,2}$ Biomedical Research Institute, Darfur College, Nyala, Sudan \\ ${ }^{1}$ Department of Medical Microbiology, Faculty of Medical Laboratory Sciences, University of Khartoum, Sudan \\ ${ }^{2}$ Department of Epidemiology and Health Statistics, School of Public Health, Southeast University, China \\ ${ }^{4}$ School of Medicine, Darfur College, Nyala, Sudan \\ ${ }^{5}$ School of Chemistry and Chemical Engineering, Southeast University, China
}

\section{Corresponding Author:}

Hassan H. Musa,

Department of Medical Microbiology,

Faculty of Medical Laboratory Sciences, University of Khartoum, Sudan.

Email: hassanhm@uofk.edu

The ongoing pandemic of novel coronavirus disease, COVID-19, which first reported in Wuhan, China, in December 2019, [1] and caused by severe acute respiratory syndrome coronavirus 2 (SARS-CoV-2) has resulted to more than 6,881,352 confirmed cases in the world, and 399,895 global deaths, as reported in 8:36am CEST, 8 June 2020 [2]. It has been reported that the primary spread of COVID-19 via human transmission is during close contact, most often through small droplets spread by coughing, sneezing, and talking [3]. Researchers and health experts have discovered that wearing of appropriate face masks can significantly reduce the transmission up to the $75 \%$.

Although, majority of people across the world were using the masks to prevent them from being infected with COVID-19 virus, these masks, on another hand after being used, are considered as medical wastes at hospital level which can easily be safe-handled by health workers and professionally-trained waste managers. COVID-19 associated used-materials at various households and community level also considered as medical wastes, instead of the normal household or municipal wastes, and is handled properly by the appropriate authorities in advanced countries of the world. However, among those in developing countries, especially in Africa and Asia where there is inadequate or lack of health awareness. These medical wastes in the form of masks, gloves, sanitary papers and clothing materials used by people during the pandemic should be considered medical wastes that require safe handling at the household level and expertise treatments at municipal level. There is fact that some people with minor COVID-19 symptoms are recovering at home via isolation, while others who are asymptomatic may not really understand that the waste trash, they are throwing out could be contaminated, generating enormous virus-laden trash. Garbage contaminated with bodily fluids or other infectious materials is becoming a bigger concern with COVID-19 pandemic [4]. On other hand, health workers involved in the waste collection, waste transport, and disposal of both urban and rural waste are in physical contact with waste materials and, because of this, are exposed the infection and physical risks to their health [5]. Therefore, sanitation workers are also worried, since the virus can persist for up to a day on cardboard and longer, on metal and plastic.

Current information on COVID-19 indicates that personal protection equipment (PPE) and other wastes that may be contaminated with the virus should be managed with, and in the same manner as medical waste [6]. Micro-management strategies towards the collection of community waste should be considered because it presents a logistical and practical global challenge for the cities' authorities in developing countries [7, 8]; where the poor handling conditions of waste associated with inappropriate use of personal protective equipment and other unfavorable conditions [9].

Therefore, to protect sanitation workers, households with residents infected or suspected to be infected with COVID-19 should carefully and tightly enclose any waste that may be contaminated with the virus in heavy-duty bags, double-bagged the waste, and ensure that curbside containers are not overfilled so the lids can close completely and possibly tightly. We recommend that people handling home wastes, in particular during COVID-19 outbreak, to clean hands with soap and water for 20 seconds or alcohol-based hand sanitizer immediately after handling COVID-19 waste, wear appropriate gear, including boots, aprons, 
long-sleeved gowns, thick gloves, masks, and goggles or face shields. According to the WHO guidelines, employers should adapt infection control strategies based on hazard assessment, using appropriate combinations of engineering and administrative controls, safe work practices, and PPEs to prevent worker exposures [10].

Furthermore, health system and health policy makers must consider the health measurements towards medical waste management at hospital and community and household levels. However, it might be a big health challenge in hand especially for community health workers, in the safe handling and appropriate disposal of medical waste at the community level and among those lacks health knowledge especially in developing and underdeveloped countries. The effective health policy must be recommended to managing waste infrastructure and enforcing sanitation practices it may be an issue of decreased the spread of COVID-19.

\section{REFERENCES}

[1] Huang, C., et al., "Clinical features of patients infected with 2019 novel coronavirus in Wuhan, China," Lancet: vol. 395, no. 10223, pp. 497-506, 2020.

[2] World Health Organization (WHO). WHO Coronavirus Disease (COVID-19) Dashboard 2020. [Online]. Available: https://covid19.who.int/

[3] World Health Organization (WHO). Water, sanitation, hygiene, and waste management for the COVID-19 virus: interim guidance. 25 April 2020|COVID-19: Infection prevention and control/WASH. [Online] Available: https://www.who.int/publications-detail/water-sanitation-hygiene-and-waste-management-for-covid-19

[4] Shi, J. and Zheng, W., "Coronavirus: China struggling to deal with mountains of medical waste created by epidemic," 5 March. 2020. [Online]. Available: https://www.scmp.com/news/china/society/article/ 3065049/ coronavirus- china-struggling-deal-mountain-medical-waste-created

[5] Porta, D., et al., "Systematic review of epidemiological studies on health effects associated with management of solid waste," Environmental Health, vol. 8, no. 60, 2009.

[6] United Nations Environment Programme (UNEP). "Waste Management and essential public service in the fight to beat COVID-19," United Nations Environment Programme, 2020. [Online]. Available: https:/www.šppinenvironment.org/news-and-stories/press-release/waste-management-essential-public-service- ghtbeat-covid-19.

[7] Cutler, S., "Mounting Medical Waste from COVID-19 Emphasizes the Need for a Sustainable Waste Management Strategy," 2020. [Online]. Available: https://ww2.frost.com/frost-perspectives/managing -the-growing-threat-ofcovid-19-generated-medical-waste/.

[8] South China morning post. Coronavirus leaves China with mountains of medical waste, 2020. [Online]. Available: https://www.scmp.com/news/china/society/article/3074722/coronavirus-leaves-china-mountains-medical-waste.

[9] Mol, M.P., and Caldas, S., "Can the human coronavirus epidemic also spread through solid waste," Waste Management Res 2020 Apr 17:0734242X20918312.

[10] World Health Organization (WHO). "Q\&A on coronaviruses (COVID-19)". 17 April 2020. Archived from the original on 14 May 2020. Retrieved 26 May 2020. 